\title{
Microwave-Alkaline Assisted Pretreatment of Banana Trunk for Bioethanol Production
}

\author{
Egwim Evans Chidi, Shittu Kudirat Oluwatisin and Komolafe Deborah \\ Biochemistry Department, Federal University of Technology, Niger State PMB 65, Nigeria
}

Received: May 01, 2015 / Accepted: July 01, 2015 / Published: August 31, 2015.

\begin{abstract}
Pretreatment is one of the most important steps in the production bioethanol from lignocellulose materials. Alkaline pretreatment is a common mean of pretreatment but microwave oven could assist its efficiency as it can reduce the pretreatment time and improve the enzymatic activity during hydrolysis. The aim of this paper is to determine lignin removal from banana trunk using microwave-assisted alkaline $\left(\mathrm{NaOH}\right.$ and $\left.\mathrm{NH}_{4} \mathrm{OH}\right)$ pretreatments. The best pretreatment conditions were used for mass pretreatment before hydrolysis and fermentation. The result shows that, optimum lignin removal was with microwave-assisted $\mathrm{NaOH}$ pretreatment with the removal of up to $98 \%$ lignin at $2 \%$ ( $w / v$ (weight/volum)) sodium hydroxide, $170 \mathrm{~W}$ microwave power at $10 \mathrm{~min}$. Microwave-assisted ammonium hydroxide pretreatment achieved $97 \%$ lignin removal at $1 \%$ ammonium hydroxide concentration and $680 \mathrm{~W}$ microwave power at $5 \mathrm{~min}$. Microwave- alkaline assisted pretreatment increased the yield and quality of fermentable sugar after enzyme hydrolysis with $\mathrm{NH}_{4} \mathrm{OH}$ and ammonium hydroxide yielding $40 \%$ and $39 \%$ of ethanol, respectively. This result reveals that, well controlled microwave- alkaline assisted pretreatment of banana trunk could effectively remove lignin and give high bioethanol yield.
\end{abstract}

Key words: Microwave, alkali, pretreatment, cellulosic, banana trunk, bioethanol.

\section{Introduction}

Bioethanol or ethyl alcohol $\left(\mathrm{C}_{2} \mathrm{H}_{5} \mathrm{OH}\right)$ is a colourless gaseous or liquid fuel derived from hydrolysis and fermentation of glucose from cellulose biomass. It is produced from distillation of ethanolic waste gotten from fermentation of cellulosic biomass [1]. Bioethanol can be produced from biomasses containing cellulose such as agricultural waste, woody materials, by-product of organic materials, forest residues, herbaceous material, municipal waste, etc. [2]. Alternative liquid fuels from various sources have been sought for many years, and since the cost of raw materials which can account up to $50 \%$ of the total production, cost is one of the most significant factors to affect the economy of alcohol, nowadays, efforts are more concentrated on using cheap and abundant raw

Corresponding author: Egwim Evans Chidi, Ph.D., associate professor, research fields: industrial biochemistry and bioprocess. E-mail: evanschidi@gmail.com, c.egwim@futminna.edu.ng. materials [3]. No other sustainable option for production of transportation fuels can match ethanol made from lignocelluloses biomass with respect to its dramatic environmental, economic and infrastructure advantages [4]. The lignocellulosic materials include agricultural residues, MSW (municipal solid wastes), pulp mill refuse, switch grass and lawn, garden wastes $[5,6]$. The structures of lignocellulose material are rigid and recalcitrant. These characteristics provide plant it mechanical support and prevent it from chemical degradation and enzymatic hydrolysis for bioethanol production [7]. Pretreatment of lignocellulose biomass for bioethanol production is an important process step done to remove lignin and hemicellulose from biomass so that the residual cellulose can be hydrolyzed to fermentable sugar [8]. Acid pretreatment of biomass result in disruption of covalent bond, hydrogen bond and Vander Waals forces holding the constituent of the biomass together therefore resulting in the solubilisation and 
decrystallization of biomass [9]. Alkali pretreatment on the other hand causes swelling of biomass through saponification reaction [10]. Alkali pretreatment disrupts the structure of lignin and breaks the bond between lignin and other cellulose component of biomass thereby increasing their susceptibility to enzymatic hydrolysis [8]. Enzymatic hydrolysis involves mixture of enzymes such as cellulose and hemicellulases [11]. These enzymes must be able to break down lignocellulosic materials and convert it to fermentable glucose [12]. Enzymatic hydrolysis has low utility lost compare to acid hydrolysis and environmental friendly [13]. Banana truck is a promising cellulose and lignocellulosic plant which generates a significant amount of waste, approximately $200 \mathrm{t} / \mathrm{ha} /$ year [14]. Despite its cellulose (63\%-64\%) and hemicellulose (19\%) content [15], it is not often used as a raw material for bioethanol production probably due to its lignin content (15.07\%). The aim of this study is to determine lignin removal of banana trunk using alkaline pretreatment $\left(\mathrm{NaOH}\right.$ and $\left.\mathrm{NH}_{4} \mathrm{OH}\right)$ microwave assisted alkaline pretreatment. The effectiveness of these pretreatments was evaluated by bioethanol yield through fermentation.

\section{Materials and Methods}

Materials used are of analytical grades unless otherwise stated. Methods followed the stages and steps as outlined.

\subsection{Collection of Samples}

Banana trunk was collected from Bosso, Minna, and was dried in an oven and grinded to powder. The sample was further sieved into smaller particles and kept for further analysis.

\subsection{Chemicals}

Sodium hydroxide $(\mathrm{NaOH})$, ammonium hydroxide $\left(\mathrm{NH}_{4} \mathrm{OH}\right)$ and distilled water.

\subsection{Chemical Pretreatment}

Banana trunk biomass was subjected to pretreatment with sodium hydroxide $(\mathrm{NaOH})$ of $2 \%, 4 \%, 6 \%, 8 \%$ and $10 \%$ concentration in the ratio $10: 1$, and then placed in the water-bath with temperature of $60,70,80$, 90 and $100{ }^{\circ} \mathrm{C}$ for $1 \mathrm{~h}$, banana trunk was also immersed in ammonium hydroxide $\left(\mathrm{NH}_{4} \mathrm{OH}\right)$ with the concentration of $1 \%, 2 \%, 3 \%, 4 \%, 5 \%$ and also placed in the water-bath for $1 \mathrm{~h}$ with the temperature ranging from $60{ }^{\circ} \mathrm{C}$ to $100{ }^{\circ} \mathrm{C}$. The mixture was then filtered with muslin cloth and the residue was washed with clean water until the $\mathrm{pH}$ was neutral and dried in an oven to remove excess water and moisture and then kept for further analysis.

\subsection{MAA (Microwave Assisted Alkaline) Pretreatment}

Banana trunk powder was immersed in $2 \%, 4 \%, 6 \%$, $8 \%$ and $10 \% \mathrm{NaOH}$ solution in the ratio of $10: 1$ of liquid to solid ( $v / w$ (volum/weight)). The mixture was then placed in a microwave oven 5, 10, 15, 20 and $25 \mathrm{~min}$ at the varying power of $170,340,510,680$ and $850 \mathrm{~W}$. After this process, the mixture was then filtered and the residue was washed with clean water until the $\mathrm{pH}$ was neutral and the dried in the oven and kept afterwards for further analysis. Also the sample was immersed in ammonium hydroxide $\left(\mathrm{NH}_{4} \mathrm{OH}\right)$ with the varying concentration of $1 \%, 2 \%, 3 \%, 4 \%$ and $5 \%$ in the ratio of 10:1 and was then placed in a microwave oven for 5, $10,15,20$ and $25 \mathrm{~min}$ at varying power of microwave oven at $170,340,510,680$ and $850 \mathrm{~W}$. The sample was then filtered and the residue was washed with clean water until the $\mathrm{pH}$ was neutral and afterwards dried in the oven to remove water and moisture. The dried residue was then kept for further analysis. Optimum condition obtained from both microwave-assisted alkaline pretreatments were used generate bulk pretreated banana trunk biomass. This biomass was thereafter hydrolyzed with cellulose and fermentation to produce bioethanol.

\section{Results and Discussion}

Lignin removal using ammonium hydroxide $\left(\mathrm{NH}_{4} \mathrm{OH}\right)$ and sodium hydroxide $(\mathrm{NaOH})$ in water bath 
pretreatments are shown in Figs. 1 and 2. The reduction in the weight of the residue is proportional to the lignin removed. The effect of $\mathrm{NH}_{4} \mathrm{OH}$ concentration is not significant on lignin removal at $60{ }^{\circ} \mathrm{C}$ and $70{ }^{\circ} \mathrm{C}$. The highest removal of legnin was observed with $2 \%$ $\mathrm{NH}_{4} \mathrm{OH}$ at $100{ }^{\circ} \mathrm{C}$. On the other hand, lowest removal of legnin was found at $100{ }^{\circ} \mathrm{C}$ with $4 \% \mathrm{NH}_{4} \mathrm{OH}$.
Concentration of $\mathrm{NaOH}$ had significant influence on lignin removal as shown in Fig. 2. It was found that, when $\mathrm{NaOH}$ concentration increased from $2 \%$ to $10 \%$, there was general reduction in the weight of residual sample at some of the experimental temperatures (70, 90 and $100{ }^{\circ} \mathrm{C}$ ). The highest biomass reduction (lignin removal) was observed with $8 \% \mathrm{NaOH}$ at $80{ }^{\circ} \mathrm{C}[16]$,

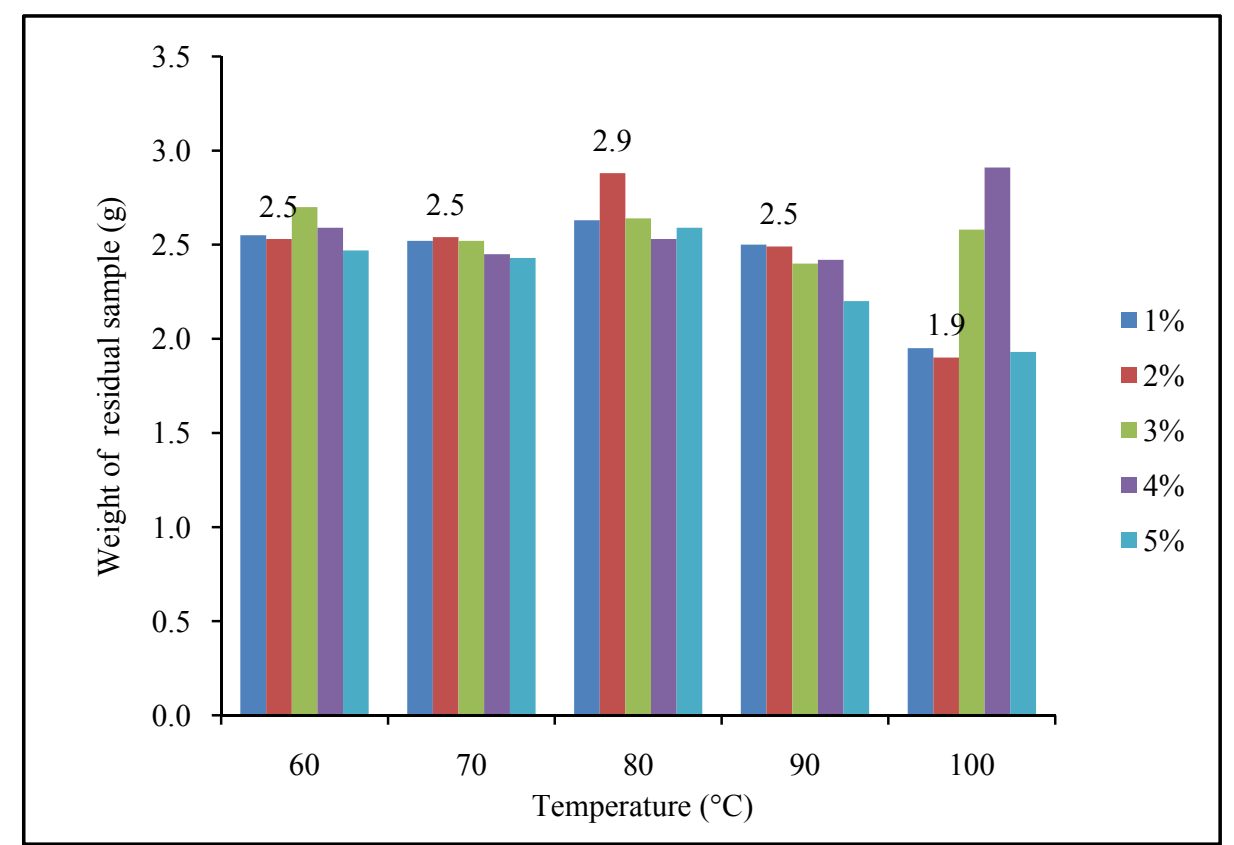

Fig. 1 Mean weight of residual biomass after pretreatment with ammonium hydroxide with the aid of water bath at different temperature.

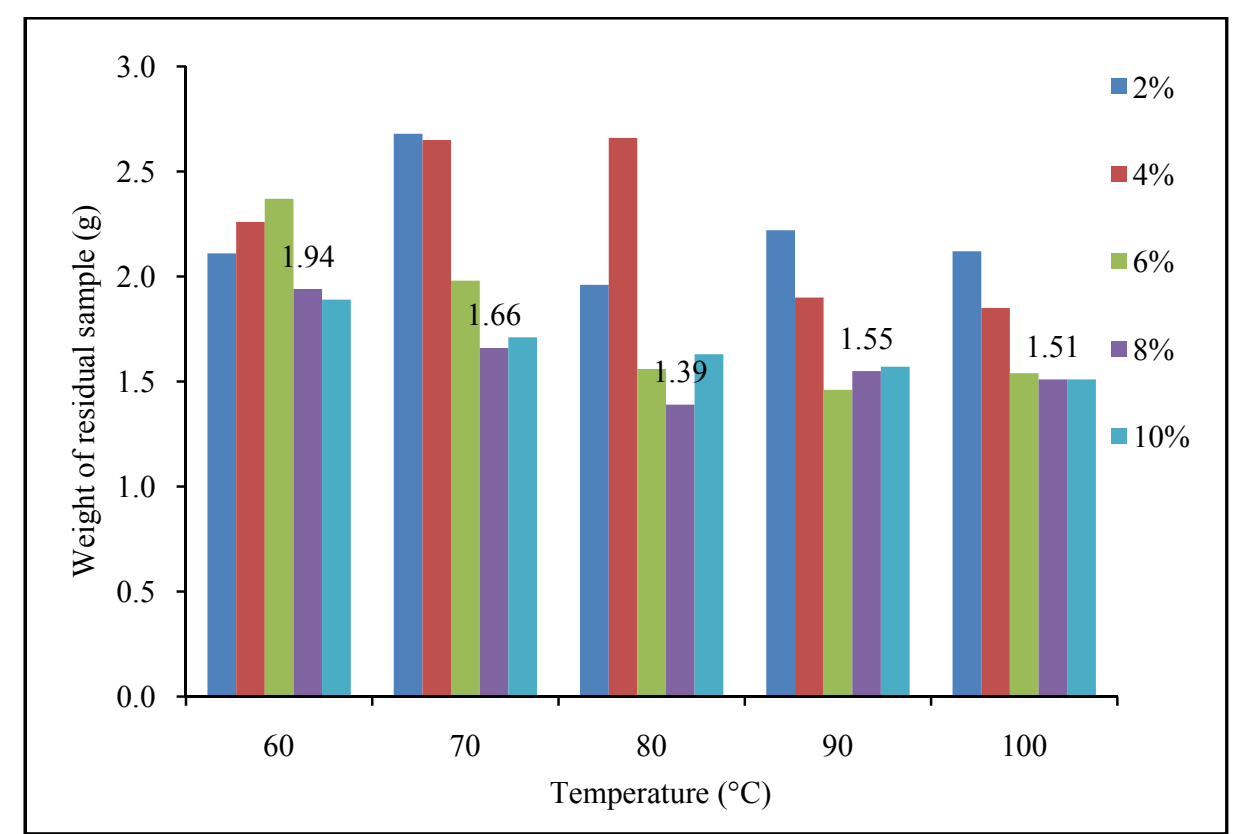

Fig. 2 Mean weight of residual biomass after pretreatment with sodium hydroxide with the aid of water bath at different temperature. 
studied the effectiveness of sulfuric acid, sodium hydroxide, hydrogen peroxide and ozone pretreatments for enzymatic conversion of cotton stalks. They found that, $2 \%$ sodium hydroxide pretreatment resulted in the highest level of delignification at $121{ }^{\circ} \mathrm{C}$. Earlier studies have shown that, $2 \%$ sodium hydroxide, would remove up to $65 \%$ lignin in corn stover [17]. Also [18] achieved over $55 \%$ reduction in the lignin content within first $0.5 \mathrm{~h}$ of pretreatment using $0.5 \%$ sodium hydroxide solution at $120{ }^{\circ} \mathrm{C}$. The pretreatment achieved in this study is in correlation with previous studies based on the suggestion of alkaline pretreatment at lower temperature with high alkaline concentration or vice versa [19]. Sodium hydroxide solution has shown to be more effective in deligninfication of banana trunk biomass than aqueous ammonium hydroxide. Sodium hydroxide is one of the most effective alkaline reagents and has been used to treat a variety of lignocellulosic feedstock [20].

\subsection{Microwave-Assisted Alkaline Pretreatment}

$\mathrm{NaOH}$ and $\mathrm{NH}_{4} \mathrm{OH}$ are dipolar reagents and the alignment and migration of their charged ions and water molecules in rapidly alternating electromagnetic field results in a friction which generate heat within a short period of time in microwave system. The electromagnetic field of microwave irradiation applies force that changes their direction rapidly at the rate of $2.4 \times 10^{9}$ times per second [21]. These characteristics can increase the process of chemical, biological and physical pretreatment [22].

$$
\text { 3.1.1 Graphical Representation of }
$$

Microwave-Assisted Sodium Hydroxide Pretreatment at Varied Time Using Surfer-11 Model

Generally, microwave assisted pretreatment using different concentrations of ammonium hydroxide yielded the lowest weight delignification at the concentration of $1 \%$ and irradiation power of $680 \mathrm{~W}$ after time $10 \mathrm{~min}$ of pretreatment. This is because extended pretreatment [23] and charring of the sample at very high temperature $(850 \mathrm{~W})$ during microwave assisted alkaline pretreatment [24] is likely to result in loss of carbohydrates to the pretreatment liquor. (Figs. 3-12). However, the present study has shown that, microwave-assisted sodium hydroxide pretreatment at $2 \%(w / v)$ concentration, $170 \mathrm{~W}$ for 10 min (Fig. 4) was the best conditions for delignification of banana trunk biomass.

The result shows a rise and fall pattern in weight of sample as the power of irradiation and concentration of sodium hydroxide is increased but shows the lowest reduction at concentration of $8 \%$ and power of $680 \mathrm{~W}$.

Microwave assisted pretreatment using different concentration of sodium hydroxide at different power shows an increase delignification as the irradiation power and concentration of $\mathrm{NaOH}$ increased. The optimum condition of pretreatment was observed at $2 \%$ $\mathrm{NaOH}$ and $170 \mathrm{~W}$ irradiation power. This optimum condition gave the overall highest delignification of banana trunk cellulose.

The pretreatment condition at 15 min shows a rise and fall pattern as the irradiation power and concentration of $\mathrm{NaOH}$ was increased, and the lowest weight of residual cellulose was 1.26 and was observed as the concentration and power were increased.

Pretreatment condition at $20 \mathrm{~min}$ shows a rise and fall pattern in the weight of residual sample. Increase in the irradiation power and concentration reduces the weight of the residual sample.

Microwave assisted pretreatment using different irradiation power and concentrations of sodium hydroxide shows a rise and fall pattern in the weight of residual cellulose, and the optimum condition was observed at $2 \% \mathrm{NaOH}$ and $170 \mathrm{~W}$ irradiation power.

3.1.2 Graphical Representation of Microwave Assisted Ammonium Hydroxide Pretreatment Using Surfer-11 Model

Microwave assisted pretreatment using ammonium hydroxide of different concentration and irradiation power shows a rise and fall pattern of residual weight but gives a sharp fall at $680 \mathrm{~W}$ of irradiation power. 


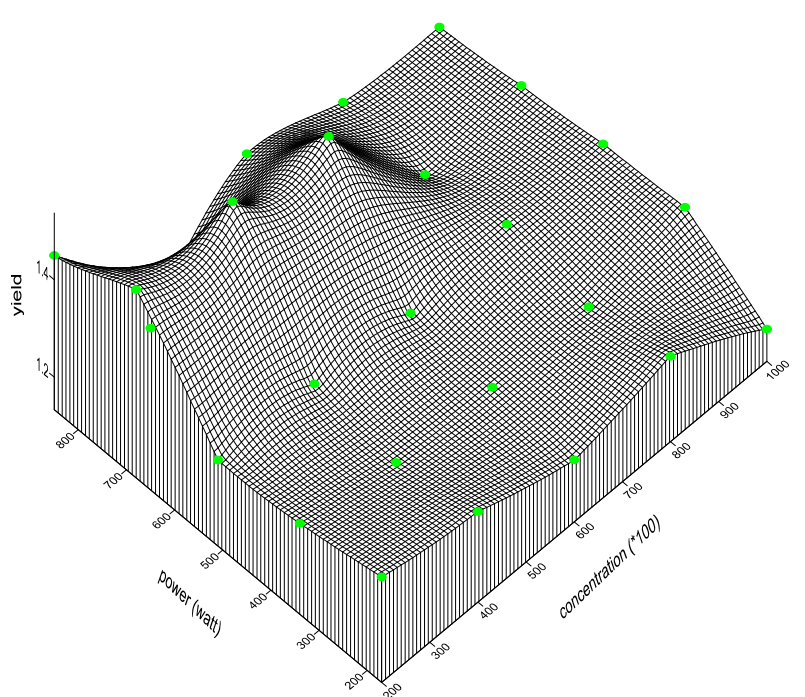

Fig. 3 Microwave assisted pretreatment using sodium hydroxide for $5 \mathrm{~min}$.

Regression coefficient Z (X, Y) = A00 + A01 (Y) + A10 (X); $\mathrm{A} 00=1.3592 ;$

$\mathrm{A} 01=7.764705882363 \times 10^{-0.05}$

$\mathrm{A} 10=-0.00136$

Coefficient of multiple determination $\left(R^{2}\right)=0.210322865663$;

Surface definition $=$ simple planar surface;

$\mathrm{X}=$ Concentration, $\mathrm{Y}=$ Power, $\mathrm{Z}=$ Weight of residual sample after pretreatment for $5 \mathrm{~min}$.

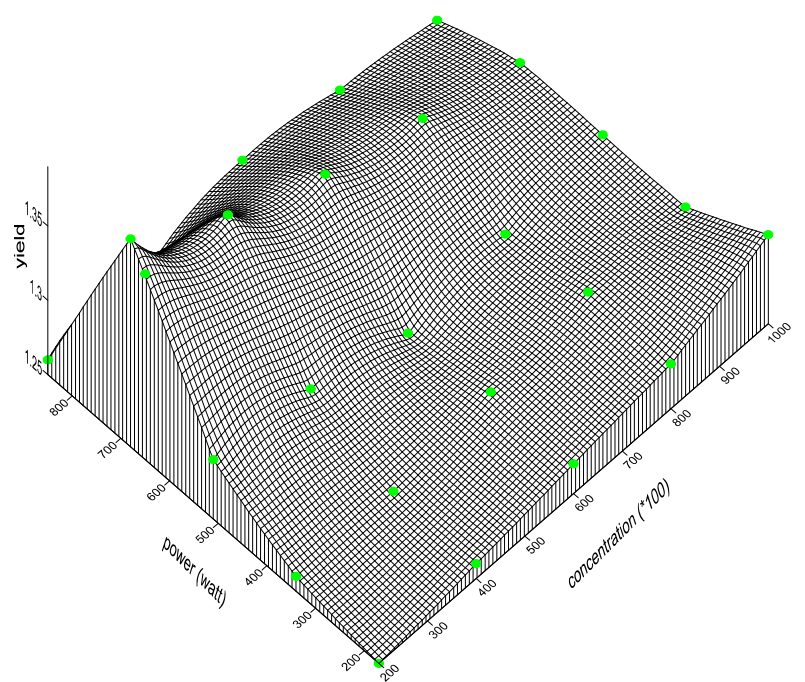

Fig. 4 Microwave assisted pretreatment using sodium hydroxide for $10 \mathrm{~min}$.

Regression coefficient Z (X, Y) = A00 + A01 (Y) + A10 (X); $\mathrm{A} 00=1.2756$

$\mathrm{A} 01=2.4706882352943 \times 10^{-0.05}$;

A10 $=-9 \times 10^{-0.05}$;

Coefficient of multiple regression $\left(R^{2}\right)=0.0436746987952$;

Surface definition $=$ simple planar surface;

$\mathrm{X}=$ Concentration, $\mathrm{Y}=$ Power, $\mathrm{Z}=$ Weight of residual sample after pretreatment for $10 \mathrm{~min}$.

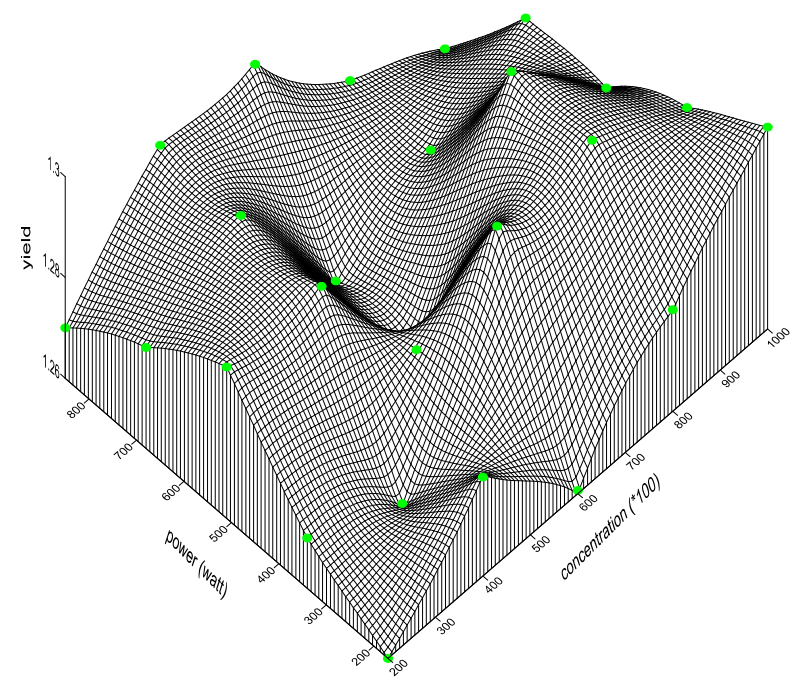

Fig. 5 Microwave assisted pretreatment using sodium hydroxide for $15 \mathrm{~min}$.

Regression coefficient Z (X, Y) = A00 + A01 (Y) + A10 (X); $\mathrm{A} 00=1.2762$

$\mathrm{A} 01=-4.7058823529407 \times 10^{-0.06} ;$

A10 $=-9 \times 10^{-0.06}$;

Coefficient of multiple regression $\left(R^{2}\right)=0.0389245585875$;

Surface definition $=$ simple planar surface;

$\mathrm{X}=$ Concentration, $\mathrm{Y}=$ Power, $\mathrm{Z}=$ weight of residual sample after pretreatment for $15 \mathrm{~min}$.

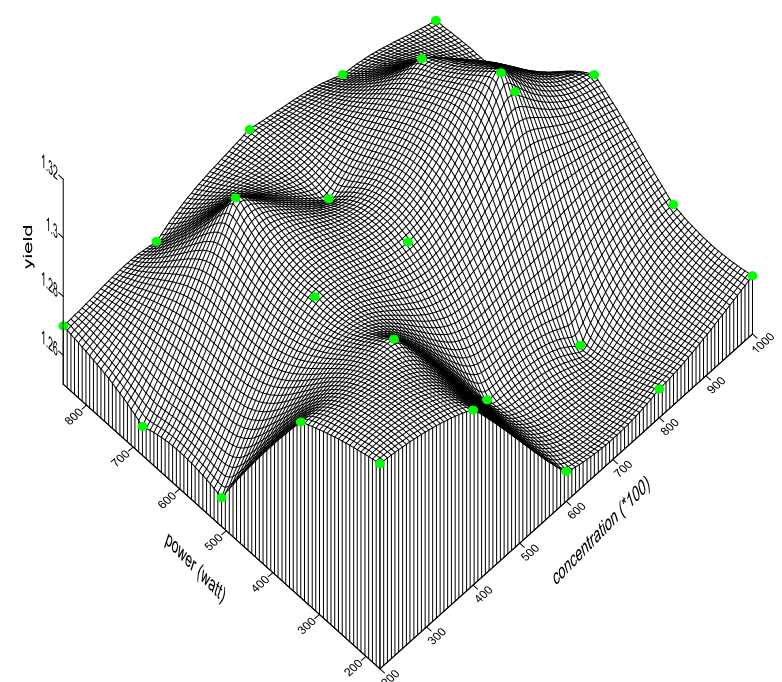

Fig. 6 Microwave assisted pretreatment using sodium hydroxide for $20 \mathrm{~min}$.

Regression coefficient Z (X, Y) = A00 + A01 (Y) + A10 (X);

A00 $=1.3038$

$\mathrm{A} 01=-1.5294117647057 \times 10^{-0.05}$;

A10 $=-2.4 \times 10^{-0.05}$

Coefficient of multiple regression $\left(R^{2}\right)=0.124832439678$;

Surface definition $=$ simple planar surface;

$\mathrm{X}=$ Concentration, $\mathrm{Y}=$ Power, $\mathrm{Z}=$ weight of residual sample after pretreatment for $20 \mathrm{~min}$. 


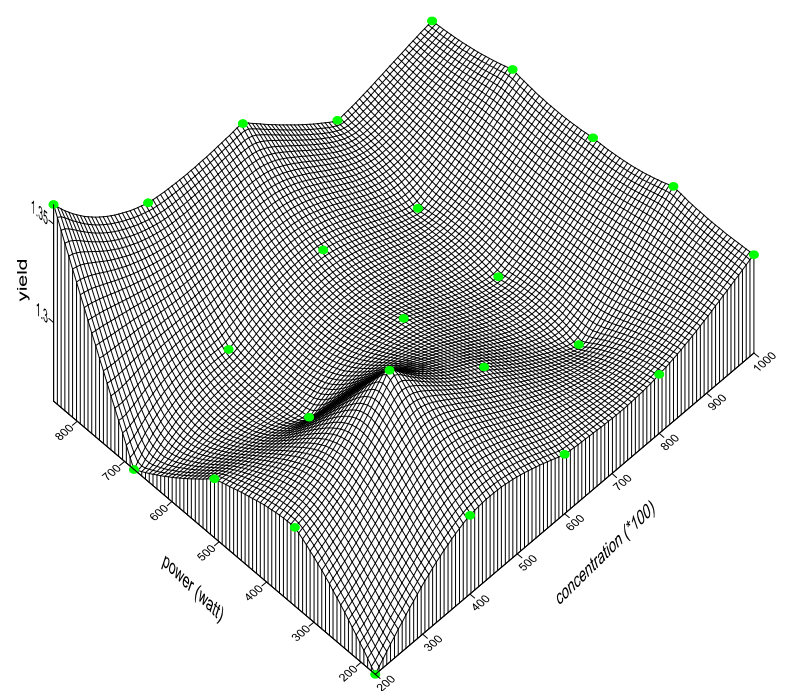

Fig. 7 Microwave assisted pretreatment using sodium hydroxide for $25 \mathrm{~min}$.

Regression coefficient Z (X, Y) = A00 + A01 (Y) + A10 (X); $\mathrm{A} 00=1.2912$;

$\mathrm{A} 01=1.4117647058825 \times 10^{-0.06}$

$\mathrm{A} 10=-6.0000000000018 \times 10^{-0.06} ;$

Coefficient of multiple regression $\left(R^{2}\right)=0.02722323049$;

Surface definition $=$ simple planar surface;

$\mathrm{X}=$ Concentration, $\mathrm{Y}=$ Power, $\mathrm{Z}=$ weight of residual sample after pretreatment for $25 \mathrm{~min}$.

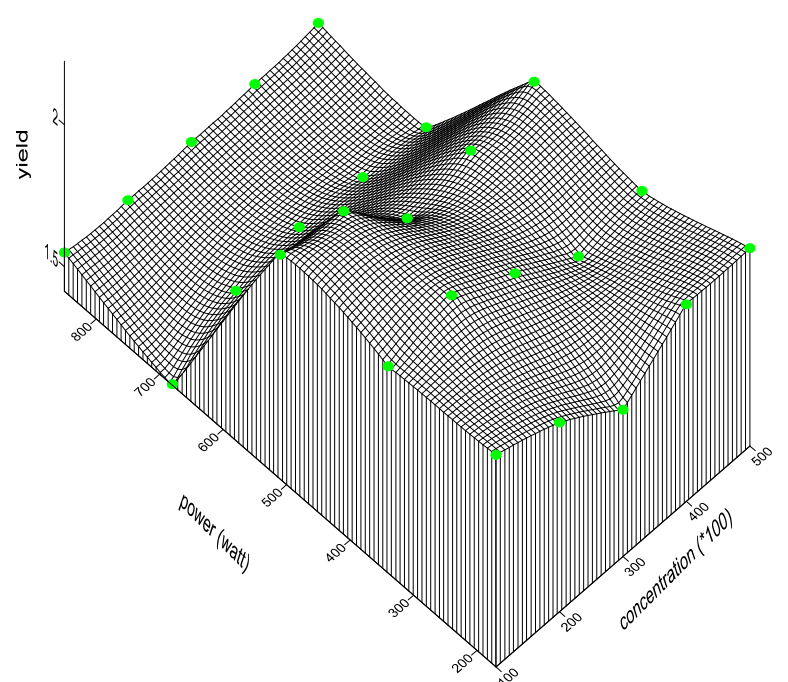

Fig. 8 Microwave assisted pretreatment using ammonium hydroxide for $5 \mathrm{~min}$.

Regression coefficient Z (X, Y) = A00 + A01 (Y) + A10 (X);

A00 $=2.3644$;

$\mathrm{A} 01=-0.00093176470688205$;

$\mathrm{A} 10=-0.000614$

Coefficient of multiple regression $\left(R^{2}\right)=0.68979218801$;

Surface definition $=$ simple planar surface;

$\mathrm{X}=$ Power, $\mathrm{Y}=$ Concentration, $\mathrm{Z}=$ weight of residual sample after pretreatment for $5 \mathrm{~min}$.

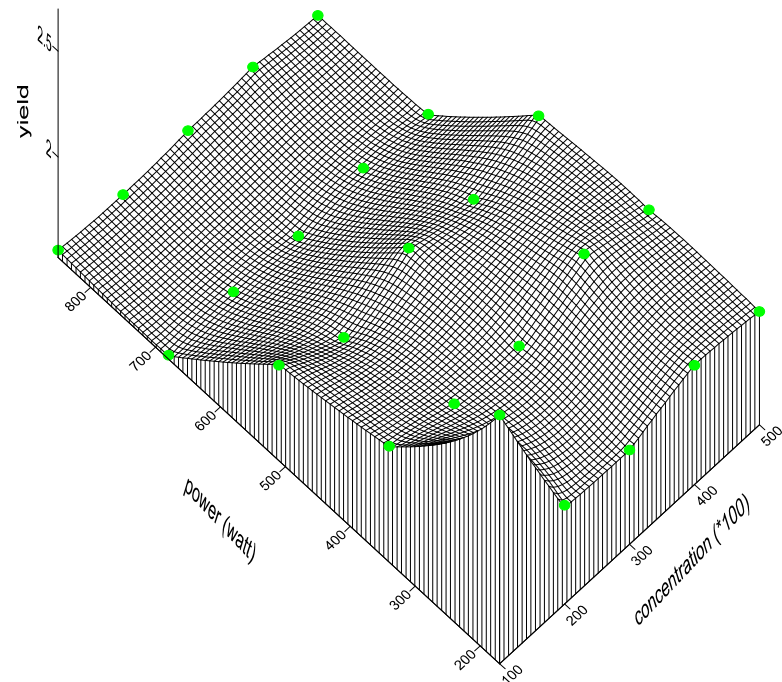

Fig. 9 Microwave assisted pretreatment using ammonium hydroxide for $10 \mathrm{~min}$.

Regression coefficient Z (X, Y) = A00 + A01 (Y) + A10 (X);

$\mathrm{A} 00=2.4112$;

$\mathrm{A} 01=0.001001764705882$;

$\mathrm{A} 10=0.000162$

Coefficient of multiple regression $\left(R^{2}\right)=0.72741588692$;

Surface definition $=$ simple planar surface;

$\mathrm{X}=$ Power, $\mathrm{Y}=$ Concentration, $\mathrm{Z}=$ weight of residual sample after pretreatment for $10 \mathrm{~min}$.

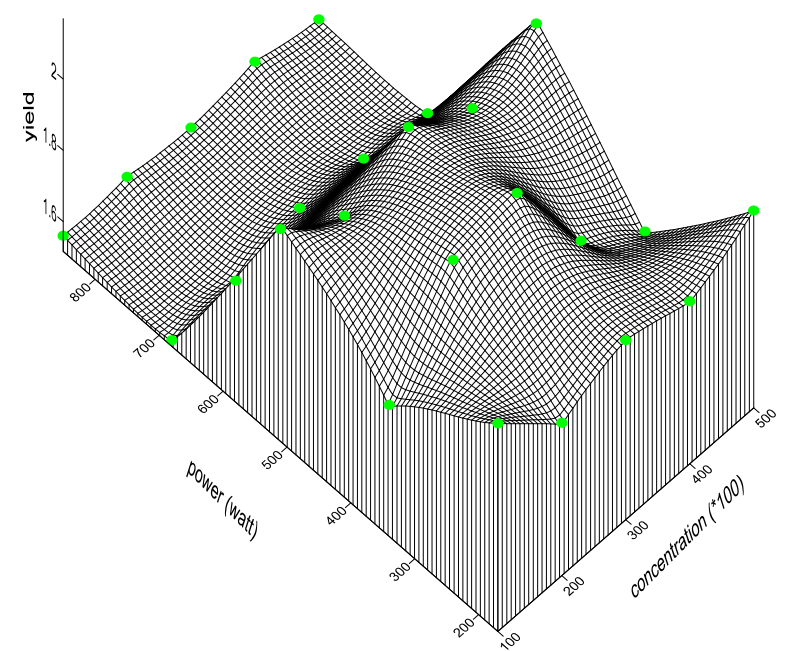

Fig. 10 Microwave assisted pretreatment using ammonium hydroxide for $15 \mathrm{~min}$.

Regression coefficient Z (X, Y) = A00 + A01 (Y) + A10 (X);

$\mathrm{A} 00=2.668$;

$\mathrm{A} 01=-0.00078$;

$\mathrm{A} 10=-0.000134 ;$

Coefficient of multiple regression $\left(R^{2}\right)=0.621727953942$;

Surface definition = simple planar surface;

$\mathrm{X}=$ Power, $\mathrm{Y}=$ Concentration, $\mathrm{Z}=$ weight of residual sample after pretreatment for $15 \mathrm{~min}$. 


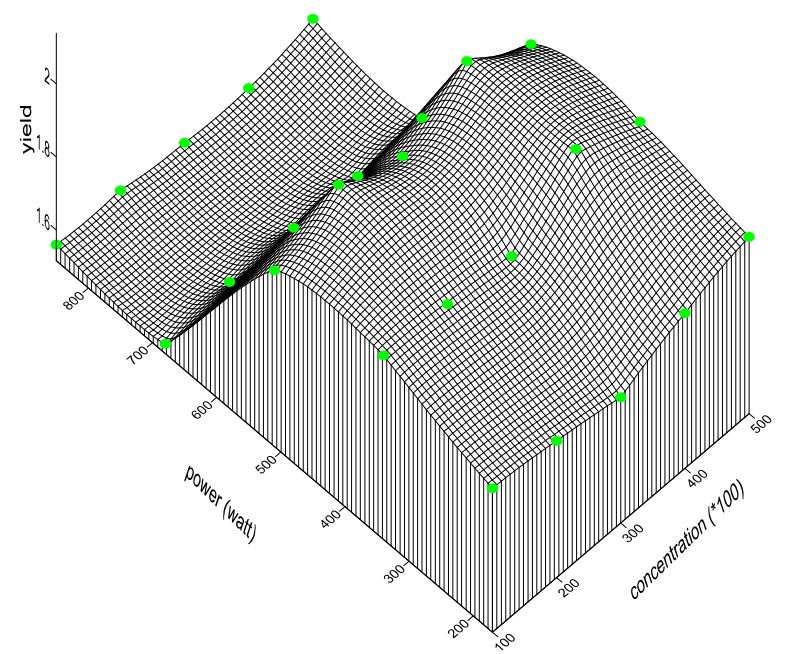

Fig. 11 Microwave assisted pretreatment using ammonium hydroxide for $20 \mathrm{~min}$.

Regression coefficient Z (X, Y) = A00 + A01 (Y) + A10 (X);

$\mathrm{A} 00=2.156$;

$\mathrm{A} 01=-0.00071647058823529 ;$

$\mathrm{A} 10=0.000114$

Coefficient of multiple regression $\left(R^{2}\right)=0.572491400311$;

Surface definition $=$ simple planar surface;

$\mathrm{X}=$ Power, $\mathrm{Y}=$ Concentration, $\mathrm{Z}=$ weight of residual sample after pretreatment for $20 \mathrm{~min}$.

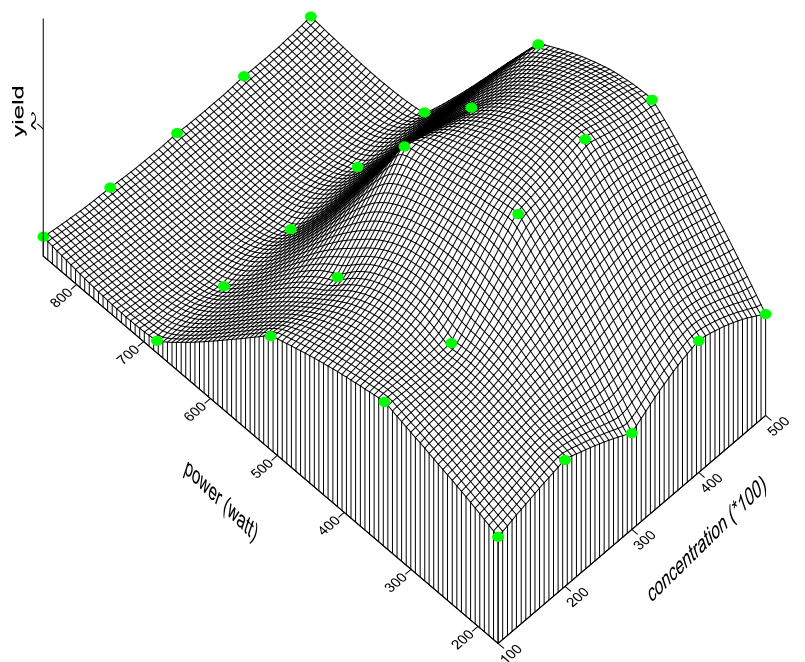

Fig. 12 Microwave assisted pretreatment using ammonium hydroxide for $25 \mathrm{~min}$.

Regression coefficient Z (X, Y) = A00 + A01 (Y) + A10 (X);

$\mathrm{A} 00=2.234$

$\mathrm{A} 01=-0.00087882352941177$;

$\mathrm{A} 10=0.000318$

Coefficient of multiple regression $\left(R^{2}\right)=0.508299550688$;

Surface definition $=$ simple planar surface;

$\mathrm{X}=$ Power, $\mathrm{Y}=$ Concentration, $\mathrm{Z}=$ weight of residual sample after pretreatment for $25 \mathrm{~min}$.
Pretreatment condition for 10 min gives a gradual reduction in weight of residual sample and a sharp decrease when the irradiation power was increased to $680 \mathrm{~W}$. The optimum condition yielding $1.53 \mathrm{~g}$ was observed at concentration of $1 \% \mathrm{NH}_{4} \mathrm{OH}$ at irradiation power $680 \mathrm{~W}$.

Pretreatment condition after $15 \mathrm{~min}$ shows a rise and fall pattern in the weight of residual cellulose and a sharp reduction was observed at $680 \mathrm{~W}$. The optimum conditions of pretreatment after 15 min were observed as the concentration and power was increased at 3\% and $5 \% \mathrm{NH}_{4} \mathrm{OH}$ and power irradiation of $680 \mathrm{~W}$ and $850 \mathrm{~W}$, respectively.

Pretreatment condition after 20 min of pretreatment with microwave irradiation shows a gradual fall in the weight of residual cellulose and a sharp reduction at $680 \mathrm{~W}$. Increase in concentration of $\mathrm{NH}_{4} \mathrm{OH}$ on the other hand produces a rise and fall pattern in the weight of residual cellulose.

Pretreatment condition after 25 min shows a gradual rise and fall in the weight of residual cellulose and a sharp decrease when power was increased to $680 \mathrm{~W}$. The optimum yield was observed at $680 \mathrm{~W}$ and $850 \mathrm{~W}$.

This implies that, low power, short time and low concentration of sodium hydroxide were required for high removal of lignin when using microwave radiation. The present observation agrees with that of [25] who observed that, the pretreatment of Bermuda grass with microwave assisted sodium hydroxide pretreatment yielded optimum result at the irradiation power of $250 \mathrm{~W}, 1 \% \mathrm{NaOH}$ concentration for 10 min which removed $65 \%$ of lignin while retaining $87 \%$ of the glucan. Furthermore, the weight of residual sample reduction in microwave-assisted sodium hydroxide pretreatment (Fig. 4) was higher than that of $\mathrm{NaOH}$ pretreatment alone (Fig. 2). This observation supports the finding of [26] who reported that, during alkali pretreatment of wheat straw, with microwave assisted heating, lower sugars losses and higher hydrolysis rates were observed than that of conventional alkaline pretreatment alone. 
Microwave assisted ammonium hydroxide pretreatment showed lowest delignification at $1 \%(w / v)$ concentration, $680 \mathrm{~W}$ under $10 \mathrm{~min}$ (Fig. 9) indicating that, high power, short time and low concentration of alkali were required for high removal of lignin. Although microwave-assisted ammonium hydroxide pretreatment yielded better delignification of banana trunk biomass at lower alkaline concentration than microwave-assisted $\mathrm{NaOH}$ pretreatment, microwave-assisted ammonium solution was considered as less efficient due to the tendency of reduced sugar yields during hydrolysis when using high power microwave assisted alkaline pretreatment [24]. However, microwave assisted ammonium hydroxide pretreatment was prefer over the convention ammonium hydroxide pretreatment alone (Fig. 1) as a result of the shorter time $(10 \mathrm{~min})$ and lower ammonium concentration ( $1 \%$ ) required. It is therefore clear from this study that, microwave assisted pretreatment achieves better delignification of banana trunk biomass than pretreatment with sodium hydroxide and ammonium hydroxide alone.

Enzymatic hydrolysis and fermentation of pretreated biomass obtained from the optimum conditions of microwave assisted sodium hydroxide pretreatment yields $300 \mathrm{~mL}$ of $40 \%$ bioethanol, while microwave-assisted ammonium hydroxide pretreatment yields $150 \mathrm{~mL}$ of $39 \%$ bioethanol. Many reports have shown that, short pretreatment duration when using microwave radiation enhances the destruction of crystalline arrangement of starch in their hydrolysis to reducing sugar [27].

\section{Conclusions}

The result obtained from this study shows that, dilute sodium hydroxide $(\mathrm{NaOH})$ of $2 \%$ at $170 \mathrm{~W}$ with microwave irradiation exposure of 10 min yields the highest amount of reducing sugar for bioethanol production. Therefore, dilute alkaline pretreatment when combined with microwave irradiation is a promising method for lignin removal from lignocellulose biomass, although more researches are still focused on how to improve this method for a better yield. The use of dilute sodium hydroxide at low irradiation power for microwave assisted alkaline pretreatment is an effective way of removing lignin from lignocellulose biomass under short period of time, and hence gives a higher turnover rate of bioethanol production.

\section{Acknowledgments}

This research was fully supported by TETFUND Institutional research grant TETFUND-Institutional-Based Research Intervention/Federal University of Tecnology Minna (TETFUND/UTMINNA)/2014/27). The authors also acknowledge the used of faclities in the STEPB (Science Technology and Post Basic) studies laboratory, Federal University of Technology Minna.

\section{References}

[1] Graeme, M. W. 2010. Bioethanol: Science and Technology of Fuel Alcohol. Copenhagen: Graeme M. Walker \& Ventus Publishing Aps, 49-52.

[2] Mustafa, B., and Havva, B. 2009. "Recent Trend in Global Production and Utilization of Bio ethanol Fuel." Applied Energy 86 (11): 2273-82.

[3] Licht, F. O. 2006. World Ethanol Markets: The Outlook to 2015. Agra Europe special report: Tunbridge Wells.

[4] Taherzadeh, M. J., and Karimi, K. 2007. "Acid-Based Hydrolysis Processes for Ethanol from Lignocellulosic Materials: A Review.” Bio Resources 2 (3): 472-99.

[5] Isa, B., Post, J., and Furedy, C. 2004. Solid Waste Management and Recycling; Actors, Partnerships and Policies in Hyderabad, India and Nairobi, Kenya. Dordrecht: Kluwer Academic Publishers.

[6] Ghosh, S., Henry, M. P., Sajjad, A., Mensinger, M. C., and Arora, J. L. 2000. "Pilot-Scale Gasification of Municipal Solid Wastes by High-Rate and Two-Phase Anaerobic Digestion (TPAD).” Water Sci. Technol. 41 (3): 101-10.

[7] Himmel, M. E., Ding, S. Y., Johnson, D. K., Adney, W. S., Nimlos, M. R., Brady, J. W., and Foust, T. D. 2007. "Biomass Recalcitrance: Engineering Plants and Enzymes for Biofuels Production.” Science 315 (5813): 804-7.

[8] Mosier, N., Wyman, C., Dale, B., Elander, R., Lee, Y. Y., Holtzapple, M., and Ladisch, M. 2005. "Features of Promising Technologies for Pretreatment of Lignocellulosic Biomass.” Bioresource Technol. 96 (6): 673-86. 
[9] Li, C., Knierim, B., Manisseri, C., Arora, R., Scheller, H. V., Auer, M., Vogel, K. P., Simmons, B. A., and Singh, S. 2010. "Comparison of Dilute Acid and Ionic Liquid Pretreatment of Switchgrass: Biomass Recalcitrance, Delignification and Enzymatic Saccharification." Bioresource Technology 101 (13): 4900-6.

[10] Xu, J., Cheng, J. J., Sharma-Shivappa, R. R., and Burns, J. C. 2010. "Sodium Hydroxide Pretreatment of Switch Grass for Ethanol Production." Energy Fuels 24 (3): 2113-9.

[11] Puwardi, R. 2006. "Continuous Ethanol Production from Dilute Acid Hydrolysate: Detoxification and Fermentation Strategy." Dept. Chemical and Biological Engineering, ChalmerTekniska, Goteborg 114 (1-2): 187-98.

[12] Sun, Y., and Cheng, J. 2012. "Hydrolysis of Lignocellulosic Materials for Ethanol Production: A Review." Bioresource Technology 83 (1): 1-11.

[13] Nurhasiken, R. B. 2010. Production of Glucose from Banana Stem Waste Using Strain A (Thesis Faculty of Chemical and Natural Resources Engineering). Malaysia: University of Malaysia Pahang.

[14] Soffner, M. L. A. O. 2001. "Pulp Production from Banana Stem." Master thesis, University of Sao Paulo.

[15] Marie-Angel, A., KEtty, B., Holmer, S. J., and Khosrow, G. 2013. "Treatment of Non-wood Plant Fibers Used as Reinforcement in Composite Materials." Materials Research 16 (4): 903-23.

[16] Silverstein, R. A., Chen, Y., Sharma-Shivappa, R. R., Boyette, M. D., and Osborne, J. A. 2007. "Comparison of Chemical Pretreatment Methods for Improving Saccharification of Cotton Stalks.” Bioresource Technology 98 (16): 3000-11.

[17] Macdonald, D. G., Bakhshi, N. N., Mathews, J. F., and Roychowdhury, A. 1983. "Alkaline Pretreatment of Corn Stover to Improve Sugar Production by Enzymatic Hydrolysis.” Biotechno. Bioeng. 25: 2067-70.

[18] Soto, M. L., Domínguez, N. M. J., and Lema, J. M. 1994.
"Enzymatic Saccharification of Alkali-Treated Sunflower Hulls." Bioresour. Technol. 49 (1): 53-9.

[19] Curreli, N., Fadda, M. B., Rescigno, A., Rinaldi, A. C., Soddu, G., Sollai, F., Vaccargiu, S., Sanjust, E., and Rinaldi, A. 1997. "Mild Alkaline/Oxidative Pretreatment of Wheat Straw." Process Biochem. 32 (8): 665-70.

[20] Sharmas, S. K., Kalar, K. L., and Grewal, H. S. 2002. "Enzymatic Saccharification of Pretreated Sunflower Stalks." Biomass Bioenergy 23 (3): 237-43.

[21] Galema, S. A. 1997. "Microwave Chemistry." Chemical Society Reviews 26 (3): 233-8.

[22] Sridar, V. 1998. Microwave Radiation as a Catalyst for Chemical Reactions." Current Science 74 (5): 446-50.

[23] Saifuddin, M. N., Refal, H., and Kumaran, P. 2013. "Microwave-Assisted Alkaline Pretreatment and Microwave Assisted Enzymatic Saccharification of Oil Palm Empty Fruit Bunch Fiber for Enhanced Fermentable Sugar Yield." Journal of Sustainable Bioenergy Systems 3 (2): 7-17.

[24] Deepak, R. K., and Jay, J. C. 2009. "Switchgrass for Bioethanol and Other Value-Added Application: A Review." Biological System Engineering 100 (4): 1514-23.

[25] Binod, P., Satyanagalakshimi, K., Sindhu, R., UshaJanu, K., Sukumaran, R. K., and Pandey, A. 2012. "Short Duration Microwave Assisted Pretreatment Enhances the Enzymatic Saccharification and Fermentable Sugar Yield from Sugarcane Bagasse.” Renewable Energy 37 (4): 109-16.

[26] Zhu, S., Wu, Y., Yu, Z., Chen, Q., Wu, G., Yu, F., Wang, C., and Jin, S. 2006. "Microwave Assisted Alkali Pre-treatment of Wheat Straw and Its Enzymatic Hydrolysis." Process Biochemistry 94 (3): 437-42.

[27] Palav, T., and Seetharaman, K. 2007. "Impact of Microwave Heating on the Physico-Chemical Properties of a Starch Water Model System." Carbohydrate Polymers 67 (4): 596-604. 